\title{
Structural and heat-insulating foam concrete of non-autoclaved hardening based on microsilica
}

\author{
Albina Baranova ${ }^{1 *}$, Pavel Shustov ${ }^{2}$, and Olga Yazina $^{1}$ \\ ${ }^{1}$ Angarsk State Technical University, Department of Industrial and Civil Engineering, 665835, Angarsk, \\ Tchaikovsky str., 60, Russia \\ ${ }^{2}$ Irkutsk National Research Technical University, 664074, Irkutsk, Lermontova str., 83, Russia
}

\begin{abstract}
The article presents testing results of non-autoclave structural and heat-insulating foam concrete, made on the basis of astringents of different grades and with different fillers. It has been experimentally established that the best filler for foam concrete is microsilica due to its high specific surface area and low bulk density in comparison with the sand. The use of high-quality binders in foam concrete mixtures allows to increase not only the strength of foam concrete, but also the content of microsilica up to $70 \%$ with respect to mixtures at lower brands of Portland cement.
\end{abstract}

The construction process involves working not only with heavy structural elements, but also with decorative concrete products designed for decoration of facades and building interiors, which are used as small architectural forms.

In connection with the increase in prices for energy carriers and the increase in heat engineering requirements for enclosing structures, there was a need to use energy-efficient building materials. One of the promising structural and thermal insulation materials is foam concrete. Due to its porous structure, foam concrete allows to keep heat in the building at the onset of winter operation, creating a perfect indoor microclimate.

The foam concrete of non-autoclaved hardening is one of the most effective materials for construction in seismically hazardous areas and regions with severe climatic conditions, such as the Irkutsk region. Products made of it allow improving, in addition to thermal properties, acoustic ones in buildings, while significantly reducing their weight. The use of non-autoclave structural and heat-insulating foam concrete reduces construction costs, labor costs and increases labor productivity.

Despite all these advantages of foam concrete, its significant disadvantage is low strength. Therefore, one of the most important tasks is to search for ways to improve its strength characteristics.

Previous studies [1-2] and analysis of literature sources [3-27] allow us to establish that the physical and mechanical properties of cellular concrete depend on the type of binder, the quality of the aggregates, the nature of the foaming agent, the additives used, the hardening conditions and many other technological factors. As a binder for the production of foam concrete it is advisable to use high-strength Portland cement with a normalized dispersion composition, and

\footnotetext{
* Corresponding author: baranova2012aa@ mail.ru
} 
industrial wastes with low bulk density can be used as a filler, such as ash from thermal power stations and microsilica.

Microsilica (MS) is formed in passing, as a result of condensation from the gas phase in the smelting of silicon alloys (ferrosilicon, silicochrome, silicomanganese). In concrete technologies, Ms application was developed in the 70s of the last century, initially primarily due to the possibility of its utilization without significant loss in the properties of concrete. The use of MS in technology is due to its ability to actively interact with $\mathrm{Ca}(\mathrm{OH})_{2}$ during the hydration of cement. The chemical activity of MS in combination with a high specific surface made it an effective component of modern cement concrete [1].

The introduction of plasticizing additives into the foam concrete mixture allows to reduce the water-cement ratio, without reducing the mobility of the mixture, and to increase the strength of the finished foam concrete. And since MS, as an ultradisperse material, has a high water demand, its use in the composition of foam concrete mixtures is expediently combined with a plasticizer.

The purpose of this work is to study the influence of the binder brand and the type of aggregate on the physico-mechanical characteristics of non-autoclave structural-thermal insulation foam.

The following materials were used in the studies: (a) the white cement of the firm "Cimsa" CEM I 52.5 R (PC 600) produced in Turkey; (b) the CeEM II/A-3 32,5B cement (PC400 D20) being produced by the JSC "Angarskcement"; (d) the sand of natural origin with the modulus of fineness $M_{k}=1.3$ (very fine) and the bulk density of $\rho_{\mathrm{n}}=1.4 \mathrm{~g} / \mathrm{cm}^{3}$; (e) microsilica from dust collecting filters of the JSC "Kremniy" with the bulk density of $\rho_{\mathrm{n}}=0.6 \mathrm{~g} / \mathrm{cm}^{3}$; (f) a hyperplasticizer based on polycarboxylates "MC-Power-Flow-3100"; and (g) a synthetic blowing agent Penta Pav 430A.

The research method was as follows. The foam concrete mixes were prepared according to the classical technology: the mortar mixture was separately prepared, consisting of a different ratio of Portland cement, sand, microsilica, sealing compounds with the addition of hyperplasticizer, and the foam (water+foaming agent). The concentration of the aqueous solution of the foaming agent was $2.5 \%$, the foam ratio was $22 \div 23$. Next, the solution mixture and the foam were mixed together until reaching a uniform consistency.

Increasing the amount of microsilica in the mixture reduces its mobility; accordingly, it is necessary to increase the water ratio and the amount of the plasticizing additive in order to provide the necessary mobility of the solution mixture. Compositions of foam concrete mixes are given in Table 1.

From the foam concrete mixes (Table 1), samples sized 40x40x160 mm were molded; on the third day, the samples were formed and placed in a normal hardening chamber. After 28 days, they were dried to constant weight at a temperature of $100 \pm 5^{\circ} \mathrm{C}$ and tested for bending and compression by a standard procedure. 
Table 1. Compositions of the foam concrete mixes.

\begin{tabular}{|c|c|c|c|c|c|c|}
\hline \multirow{2}{*}{$\begin{array}{c}\text { No. } \\
\text { composition }\end{array}$} & \multicolumn{6}{|c|}{ Content of components of foam concrete mixture, \% of the mass of solids } \\
\cline { 2 - 7 } & PC 400 D20 & PC 600 & Sand & MS & Water & Hyperplasticizer \\
\hline 1 & 30 & - & 70 & - & 0,15 & 0,33 \\
\hline 2 & 40 & - & 60 & - & 0,15 & 0,28 \\
\hline 3 & 50 & - & 50 & - & 0,15 & 0,14 \\
\hline 4 & 30 & - & - & 70 & 0,5 & 1,0 \\
\hline 5 & 40 & - & - & 60 & 0,5 & 0,9 \\
\hline 6 & 50 & - & - & 50 & 0,5 & 0,8 \\
\hline 7 & 30 & - & 35 & 35 & 0,33 & 0,65 \\
\hline 8 & 40 & - & 30 & 30 & 0,31 & 0,63 \\
\hline 9 & 50 & - & 25 & 25 & 0,31 & 0,61 \\
\hline 10 & - & 30 & 70 & - & 0,15 & 0,33 \\
\hline 11 & - & 40 & 60 & - & 0,15 & 0,22 \\
\hline 12 & - & 50 & 50 & - & 0,15 & 0,11 \\
\hline 13 & - & 30 & - & 70 & 0,5 & 1,0 \\
\hline 14 & - & 40 & - & 60 & 0,5 & 0,9 \\
\hline 15 & - & 50 & - & 50 & 0,5 & 0,8 \\
\hline 16 & - & 30 & 35 & 35 & 0,33 & 0,65 \\
\hline 17 & - & 40 & 30 & 30 & 0,31 & 0,63 \\
\hline 18 & - & 50 & 25 & 25 & 0,33 & 0,61 \\
\hline
\end{tabular}

The results are shown in Table 2 and in Figures 1-4.

Table 2. Physical and mechanical characteristics and coefficients of constructive quality (C.C.Q) of the structural and heat-insulating foam concrete.

\begin{tabular}{|c|c|c|c|c|c|c|}
\hline \multirow{2}{*}{$\begin{array}{c}\text { No. } \\
\text { composition }\end{array}$} & $\begin{array}{c}\text { Density in } \\
\text { wet } \\
\text { condition, } \\
\mathrm{kg} / \mathrm{m}^{3}\end{array}$ & $\begin{array}{c}\text { Density in } \\
\text { dry } \\
\text { condition, } \\
\mathrm{kg} / \mathrm{m}^{3}\end{array}$ & $\begin{array}{c}\text { Humidity, } \\
\%\end{array}$ & \multicolumn{2}{|c|}{ Strength, MPa } & \multirow{2}{*}{$\begin{array}{c}\text { C.C.Q }= \\
\mathrm{R}_{\mathrm{cm}} / \rho_{\text {bn }}\end{array}$} \\
& 1133 & 1041 & 8,8 & 1,30 & 3,04 & 2,92 \\
\hline 1 & 1173 & 1042 & 12,6 & 1,98 & 2,48 & 2,38 \\
\hline 2 & 1077 & 924 & 16,6 & 0,94 & 1,23 & 1,33 \\
\hline 3 & 1332 & 942 & 41,4 & 3,84 & 12,54 & 13,31 \\
\hline 4 & 1376 & 966 & 42,4 & 4,40 & 17,46 & 18,07 \\
\hline 5 & 1191 & 853 & 39,6 & 3,09 & 7,88 & 9,24 \\
\hline 6 & 1020 & 791 & 28,9 & 1,54 & 2,3 & 2,91 \\
\hline 7 & 1197 & 955 & 25,4 & 2,79 & 6,76 & 7,08 \\
\hline 8 & 1016 & 795 & 27,8 & 1,74 & 3,7 & 4,65 \\
\hline 9 & 974 & 885 & 10,1 & 0,76 & 1,2 & 1,36 \\
\hline 10 & 1021 & 901 & 13,3 & 1,39 & 3,16 & 3,51 \\
\hline 11 & 1100 & 939 & 17,2 & 0,87 & 1,9 & 2,02 \\
\hline 12 & 1375 & 955 & 44,0 & 5,78 & 26,84 & 28,11 \\
\hline 13 & 1354 & 948 & 42,8 & 4,38 & 21,40 & 22,57 \\
\hline 14 & 1239 & 901 & 37,5 & 2,8 & 11,48 & 12,74 \\
\hline 15 & 986 & 764 & 29,1 & 0,9 & 2,16 & 2,83 \\
\hline 16 & 1042 & 819 & 27,2 & 2,23 & 4,88 & 5,96 \\
\hline 17 & 949 & 746 & 27,2 & 1,89 & 4,5 & 6,03 \\
\hline 18 & & & & & & \\
\hline
\end{tabular}



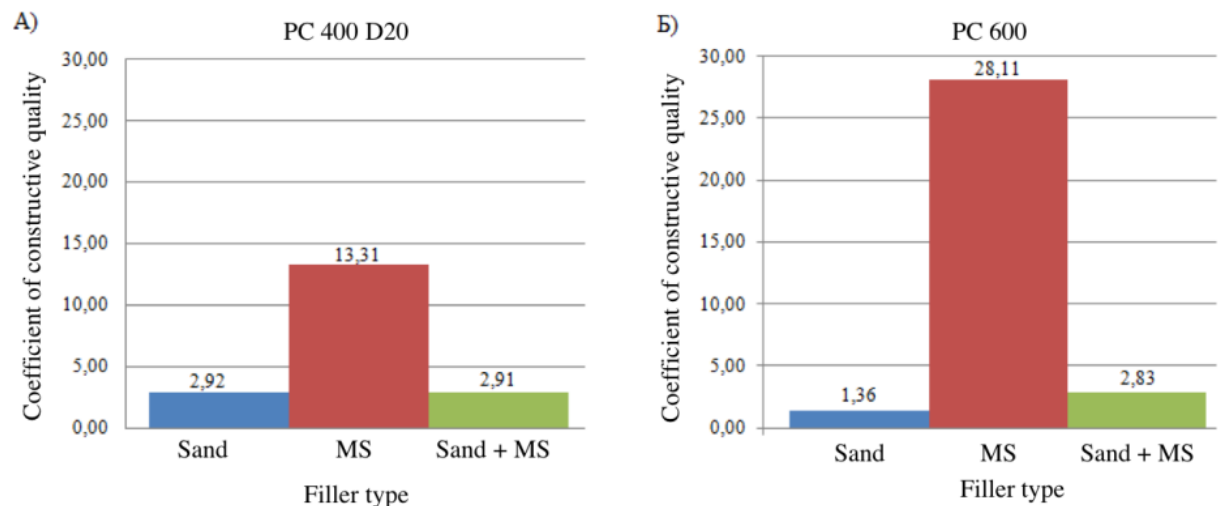

Fig. 1. Coefficients of the constructive quality of foam concrete with, containing the binder (30\%) and aggregate (70\%): A) - for compositions at PC 400 D20, B) for compositions at PC 600.
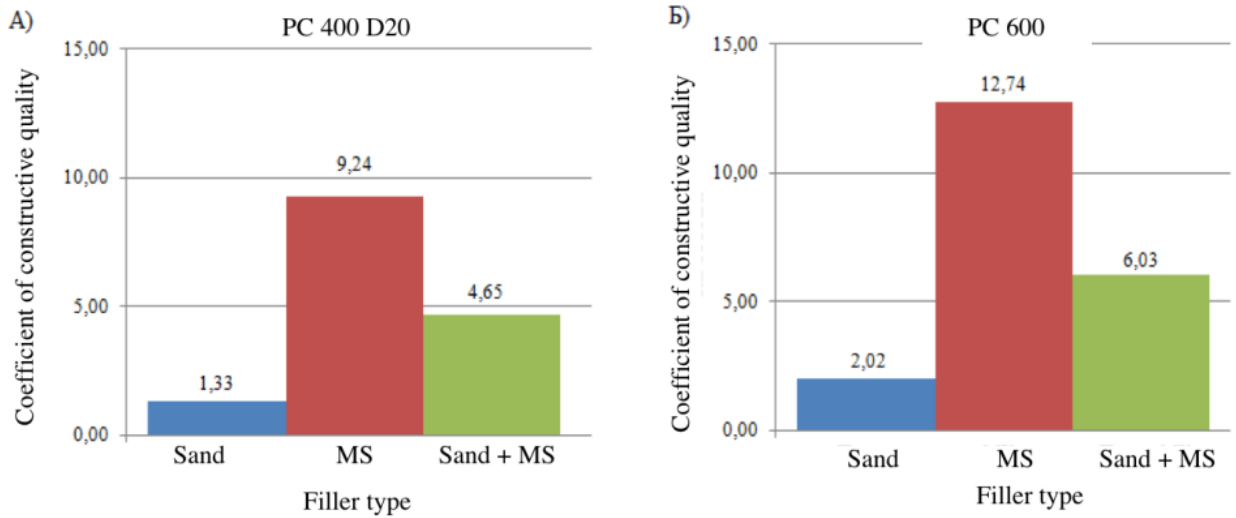

Fig. 2. Coefficients of the constructive quality of foam concrete, containing the binder (40\%) and aggregate (60\%): A) - for compositions at PC 400 D20, B) for compositions at PC 600.
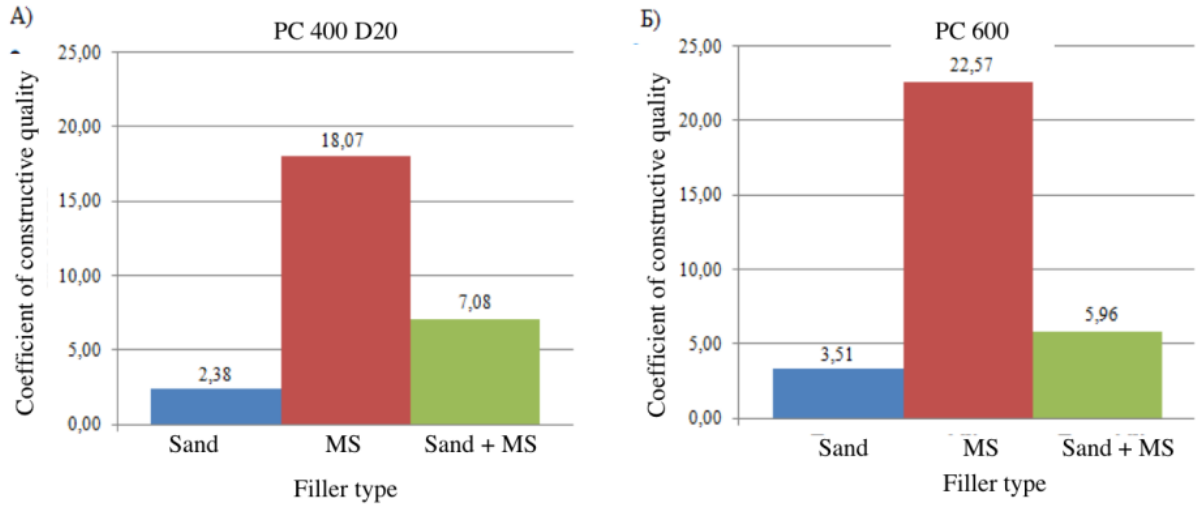

Fig. 3. Coefficients of the constructive quality of foam concrete, containing the binder (50\%) and aggregate (50\%): A) - for compositions at PC 400 D20, B) for compositions at PC600. 

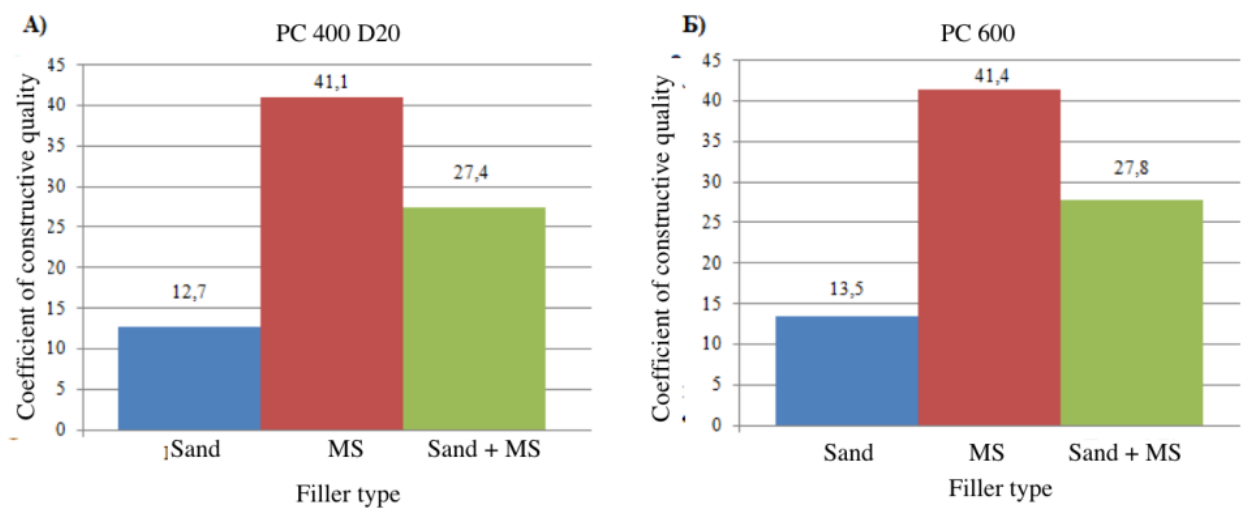

Fig. 4. An average moisture of the foam concrete samples: A) - for compositions at PC 400 D20, B) for compositions at PC 600.

From the data in Table 2 and Figures 1-3, it can be clearly seen that the maximum coefficient of constructive quality, and, consequently, the increased strength characteristics are showed by those compositions that are based on microsilica and high-strength Portland cement CEM I 52.5 $\mathrm{R}$ (PC 600). However, the moisture content of the foam concrete samples containing microsilica as a filler is more than three times higher than that of sand samples (Figure 4).

It has been experimentally established that the composition of the non-autoclaved structural and heat-insulating foam concrete (number 13 in Table 1), being made on the high-strength Portland cement CEM I 52.5 R (PC 600) and containing as microsilica a filler in an amount of $70 \%$ of the solids' mass, possesses the compressive strength of $26.84 \mathrm{MPa}$, the bending strength of $5.78 \mathrm{MPa}$, with an average density of $955 \mathrm{~kg} / \mathrm{m}^{3}$.

Thus, it can be concluded that of the two types of investigated aggregates, microsilica is the best for foam concrete. This is because of the fact that due to the high specific surface area and low bulk density of microsilica, the content and increase in its amount in the foam concrete mixture contributes to thickening the interporal partitions of the foam concrete and reducing its total porosity. Using high-quality binders in the foam concrete mixtures allows increasing not only the strength of foam concrete, but also the content of MK up to $70 \%$ with respect to the mixtures made of Portland cement obtained from lower brands.

\section{References}

1. A. Baranova, A. I. Savenkov, Proceedings of Irkutsk State Technical University, 78-82 (2014).

2. A. Baranova, A. I. Savenkov, Modern technologies and scientific and technical progress, 106-107 (2016)

3. P. Onprom, K. Chaimoon, R. Cheerarot, AMSE (2015)

4. K. Jitchaiyaphum, T. Sinsiri, C.Jaturapitakkul et al, IJMMM, 462-471 (2013)

5. W. Hu, R.D. Neufeld, L.E. Vallejo et al., JEE-ASCE, 44-54 (1997)

6. A. Hajimohammadi, N. Tuan, P. Mendis, C\&CC, 164-171 (2018)

7. T. Litsomboon, P. Nimityongskul, N. Anwar, 2nd International Conference on Advances in Concrete and Structures, 379 (2009)

8. Z. Zhang, J. L. Provis, A. Reid et al., CBM, 113-127 (2014)

9. J. L. Alvarez, N. Vega, MDC, 39-44 (1996)

10. Tiwari, B. Ajmera, D. Villegas, JMCE, 297-300 (2018) 
11. R. Kumar, R. Lakhani, P. Tomar, JCP, 1650-1663 (2018)

12. V. A. Abyzov, ICE, 783-789 (2017)

13. H. K. Lee, S. Y. Song, JRPC, 883-898 (2010)

14. L. M. Vesova, ICIE, 1587-1590 (2016)

15. A. Kashani, Tuan Duc Ngo, Priyan Mendis et al., JCP, 925-935 (2017)

16. M. Baranov, Building Materials, 28-29 (2009)

17. M. V. Krasnov, Bulletin of the MGSU, 187-189 (2009)

18. N. N. Eliseeva, Izvestiya PUPS, 226-238 (2010)

19. M. N. Baev, Yu. V. Shchukin, Polzunovsky Herald, Thermal insulating non-autoclave foam concrete with increased characteristics, p. 35-37 (2011)

20. E. A. Barteneva, N. A. Mashkin, Modern Construction and Architecture, 15-17 (2017)

21. E. V. Lukash, M. I. Kuzmenkov, SM, 33-35 (2012)

22. V. N. Rozhin, A. D. Egorova, A. E. Mestnikov, PGS, 27-29 (2013)

23. G. I. Chernousenko, A. O. Grechman, S.V. Gurov, TB, 11-13 (2014)

24. E. A. Khudovekova, A. V. Artamonova, K. M. Voronin, Resource energy-efficient technologies in the construction complex of the region, 103-107 (2014)

25. Ya. Z. Afashagova, Bulletin of the DNASA, 84-86 (2015)

26. E.V. Eruslanova, V. K. Zhugar, A. I. Gabitova, N. M. Krasinikova, RTSKR, 77-80 (2015).

27. A. I. Kudyakov, A. B. Steshenko, Bulletin of TGASU, 127-133 (2014) 